\title{
EDUCAÇÃO AMBIENTAL: TECENDO TRILHAS, ESCRITURANDO TERRITÓRIOS
}

\author{
Shaula Maíra Vicentini de Sampaio* \\ Leandro Belinaso Guimarães**
}

RESUMO: $O$ presente trabalho indaga sobre as estratégias educativas articuladas nas chamadas trilhas interpretativas de Educação Ambiental. Pergunta-se: que territórios são esses que recebem guias e estudantes em atividades de Educação Ambiental? Que perguntas são instituídas no decorrer do ato de caminhar? Quais são deixadas de ser enunciadas? Quais são as marcas que fazem de determinado percurso uma trilha? Quais territórios e quais trilhas conformam os caminhos percorridos pela Educação Ambiental? Para discorrer em torno dessas indagações o artigo foca duas experimentações diferentes. Primeiramente, abordam-se alguns aspectos referentes à construção de uma trilha interpretativa na comunidade do Pântano do Sul, em Florianópolis/SC. Sobre essa trilha, planejada para ser executada com alunos do ensino fundamental, indaga-se, sobretudo, sobre o processo que culminou na elaboração de seu traçado. $\mathrm{Na}$ segunda parte do trabalho, focam-se as trilhas interpretativas desencadeadas em um Parque Estadual de Proteção Ambiental localizado nas proximidades de Porto Alegre/RS. Para tanto, mostram-se os processos de disciplinamento dos sujeitos que estão em jogo nessas iniciativas, bem como a produção discursiva de uma natureza intangível operada nessas ações. As análises empreendidas no ensaio estão situadas no campo multifacetado e contestado dos estudos culturais. A partir desse campo, o trabalho discorre sobre as leituras da natureza que estariam sendo construídas nas atividades de Educação Ambiental focadas neste ensaio: as chamadas trilhas interpretativas. E mais, a partir dos estudos culturais indaga-se a instituição dos entendimentos sobre a natureza (e dos modos de agir em relação a ela) a partir das práticas e dos discursos envolvidos desde o planejamento e a implantação de uma trilha interpretativa, até o momento em que é desenvolvido um trabalho educativo em tais espaços.

Palavras-chave: Estudos Culturais; Trilhas Interpretativas; Educação Ambiental.

\footnotetext{
* Doutoranda em Educação pelo Instituto de Ciências Biológicas e da Saúde da Universidade Federal de Alagoas (UFAL); Professora Assistente do curso de Licenciatura em Ciências Biológicas da Universidade Federal de Alagoas (UFAL).E-mail: shaula.maira@uol.com.br

** Doutor em Educação pela Universidade Federal do Rio Grande do Sul (UFRGS); Professor do Programa de Pós-Graduação em Educação (PPGE) da Universidade Federal de Santa Catarina (UFSCar).E-mail:lebelinaso@uol.com.br
} 


\section{ENVIRONMENTAL EDUCATION: \\ WEAVING TRAILS, WRITING TERRITORIES}

ABSTRACT: This paper inquires into the educational strategies used in the so-called interpretative tracks for environmental education. We ask, 'Which territories are those receiving guides and students in environmental educational activities? Which questions are made when walking? Which are not made? Which features turn a route into a track? Which territories and tracks shape the ways for environmental education? To approach these questions the paper will focus on two different trials. First we have approached some aspects of the construction of an interpretative track in the community of Pântano do Sul in Florianópolis, SC. About this track, meant to be performed with students from primary schools, above all, we inquire into the process culminating in designing its lines. In the second part, we have focused on the interpretative tracks in a state reserve near Porto Alegre, RS. To do so, processes of disciplining subjects, and discursive production of an untouched nature, are necessary. Analyses conducted in the essay are in the challenged multi-faceted cultural studies field. In this field, work is carried out into readings on nature in the environmental education activities focused in this essay: the so-called interpretative tracks. Furthermore, from the cultural studies we can inquire into the understandings on nature (and the way we act regarding it), from practices and discourses involved from planning and using an interpretative track to the moment when an educational work is developed in such spaces.

Keywords: Cultural Studies; Interpretative Tracks; Environmental Education.

\section{Introdução}

Gostaríamos de iniciar este trabalho perguntando sobre os motivos que nos levam a escrever sobre Educação Ambiental. E mais: desejamos indagar sobre algumas razões que nos provocam a escrever sobre os modos pelos quais alguns trabalhos em Educação Ambiental têm concebido as chamadas trilhas interpretativas, comumente realizadas em territórios considerados como possuidores de alguma biodiversidade, que poderia ser contemplada por meio de suas plantas, de seus animais e de seus fungos. Refletimos, ainda, sobre como os próprios territórios percorridos através de tais trilhas vão sendo, eles próprios, narrados e, portanto, instituídos como interessantes para atividades chamadas de Educação Ambiental. Em outras palavras, nos perguntamos: que territórios são esses que recebem guias e estudantes em atividades de Educação Ambiental? Que perguntas são instituídas no decorrer do ato de caminhar? Quais são deixadas de ser enunciadas? Quais são as marcas que fazem de determinado percurso uma trilha? Quais territórios e quais trilhas conformam os caminhos percorridos pela Educação Ambiental? 
Voltando à frase que inaugura este ensaio, queremos dizer que nossa motivação para escrever sobre territórios, trilhas e Educação Ambiental é a nossa experimentação anterior com tais espaços e caminhos. Quando assumimos a condição de professores escolares de Ciências, muitas vezes levamos nossos alunos a percorrerem trilhas em parques. Já quando nos posicionamos como educadores ambientais, fomos, nós mesmos, construtores de trilhas e guias de estudantes. $\mathrm{Na}$ condição de pesquisadores pós-graduados, estamos retornando a esses dois espaços profissionais, através deste ensaio, para lançar algumas perguntas. $\mathrm{Na}$ época em que atuávamos nos projetos que serão destacados neste trabalho, acreditávamos que não tínhamos, ainda, as ferramentas necessárias para formulá-las. Fazíamos, certamente, outras indagações e aqui não queremos dizer que, agora, temos as melhores e mais elaboradas perguntas. Não! Ao ocuparmos outro lugar, o de pesquisadores, nossos olhares passaram a atentar para alguns outros aspectos relativos às trilhas de Educação Ambiental. E são essas indagações, formuladas sob inspiração do campo multifacetado dos estudos culturais, que queremos compartilhar com nossos leitores e nossas leitoras.

Nas duas seções seguintes, nos debruçamos sobre nossos trabalhos anteriores, enquanto guias de estudantes em trilhas de Educação Ambiental, sugerindo algumas reflexões, sobretudo com relação às perguntas que são formuladas nesses caminhos. A primeira parte foca o trabalho desenvolvido pelo autor na comunidade pesqueira do Pântano do Sul, em Florianópolis/SC. A segunda seção debruça-se sobre as atividades desenvolvidas pela autora em um Parque Estadual localizado no município de Viamão/RS, próximo a Porto Alegre. A partir da incursão que fazemos neste artigo, ao questionar e refletir sobre tais experiências educativas que envolvem trilhas, temos a intenção de suscitar perguntas, interrogações concernentes a alguns aspectos que podem parecer suficientemente certos, naturais e evidentes no que tange às atividades de Educação Ambiental que são conduzidas em trilhas. Assim, esperamos, com este ensaio, provocar a elaboração de um conjunto amplo de perguntas sobre as e nas trilhas que comumente vêm sendo produzidas e executadas em diferentes trabalhos de Educação Ambiental. Desejamos que perguntas diversas possam ser experimentadas nos trajetos que percorremos com nossos alunos, pois, como mostraremos, parece que estamos vivendo um período de saturação dos questionamentos que 
emergem nas trilhas de Educação Ambiental, ou seja, parece que eles são quase sempre os mesmos.

\section{Uma trilha repleta de urbanidades e estranhamentos...}

Nesta seção, vamos focar uma experimentação em Educação Ambiental desenvolvida nos anos de 2001 e 2002, na comunidade do Pântano do Sul, em Florianópolis/SC. O projeto, em linhas gerais, bem como alguns resultados, foram sistematizados e apresentados no I EPEA ${ }^{1}$ (GUIMARÃES; SANTOS, 2001). Neste trabalho, pretendemos refletir sobre apenas uma atividade desencadeada no âmbito daquele projeto, que pretendia, em seus objetivos gerais, capacitar os professores da escola da comunidade para a elaboração e a execução de ações em Educação Ambiental com seus alunos. Para tanto, nossa intenção central foi capturar elementos da história local para a incorporação nas atividades que desenvolveríamos. Nessa direção, selecionamos uma temática ${ }^{2}$ (a água) e, entre as diversas atividades desencadeadas (algumas com os professores e outras com os alunos), mapeamos e elaboramos uma trilha. Esta, em seu traçado, percorria vários lugares da comunidade do Pântano do Sul e visava à narração de histórias sobre a água; histórias estas coligidas a partir de narrativas orais, de depoimentos dados por pessoas que vivenciaram os diferentes momentos da ocupação e da transformação urbana por que passara o Pântano do Sul no decorrer dos tempos. Naquele momento, ainda imersos na execução do projeto e da trilha, escrevemos:

As narrativas orais coletadas com antigos moradores nos mostraram interessantes ações desenvolvidas antigamente para a obtenção de água a fim de suprir as necessidades nas poucas casas que havia. Contavam-nos, por exemplo, que até meados do século $\mathrm{XX}$, as mulheres buscavam água nas cascatas e traziam-na para suas casas através de potes de barro. Com o crescimento populacional, mais intensificado a partir dos anos sessenta, houve a necessidade de se canalizar a água das cachoeiras. Inicialmente, esta canalização destinava-se, apenas, para a igreja católica da comunidade, passando esta a ser o principal ponto de coleta de água no Pântano do Sul. Depois, a canalização foi feita para cada uma das casas existentes. Em seguida, já nos anos sessenta ou setenta (não foi possível precisar datas), foi construída uma rede de captação e distribuição de água pela Associação de 
Moradores do Pântano do Sul. A comunidade cresceu mais e houve necessidade, já nos anos oitenta, de se construir um poço artesiano para aumentar a quantidade de captação de água (GUIMARÃES; SANTOS, 2001).

Foram essas, entre outras, as histórias que selecionamos para serem contadas no decorrer da trilha. Selecionamos pontos de parada e neles contávamos e recontávamos as histórias que aprendemos com os antigos moradores da comunidade. Após situar os leitores e as leitoras no contexto de elaboração da nossa trilha no Pântano do Sul, passamos, agora, a destacar quatro aspectos dessa experiência.

Primeiramente, gostaríamos de acentuar que rechear de urbanidade uma trilha de Educação Ambiental (que comumente está restrita a aspectos tidos como mais próprios à natureza) nos parece ser muito importante. Aliás, o que, em uma trilha, poderia ser visto como próprio à natureza e, por outro lado, o que seria relativo à cultura? A natureza, acreditamos, vai sendo significada através da e na arena cultural (GUIMARÃES, 2006), ou seja, aquilo que vamos entendendo ser a natureza diz respeito às disputas em torno, por exemplo, de como um território deveria ser ocupado e/ou protegido e/ou modificado e/ou preservado e/ou transformado e/ou conservado. E mais: tais disputas são configuradas historicamente, apresentando acentuações distintas em diferentes momentos. Um território visto como passível de transformação e progresso, tal como a Amazônia foi pensada pelos viajantes brasileiros da Primeira República (1889-1930) - Euclides da Cunha e Cândido Rondon -, passa a ser visto, anos depois, como passível de proteção e cuidado, sobretudo após a emergência dos movimentos ecológicos de contracultura dos anos 1970. Nessa direção de pensamento, avaliamos que foi privilegiada, em nosso projeto, uma trilha que não teceu distinções muito precisas entre o espaço natural e o espaço urbano daquela comunidade. Traçamos um caminho que se edificou em um entrelugar (SANTIAGO, 2000), ou seja, como não relativo, apenas, à natureza ou, então, à cultura, mas repleto, ao mesmo tempo, de naturezas e de urbanidades. Aliás, há algum território que possamos dizer que não esteja imbuído de marcações humanas?

Um segundo ponto a ser destacado é o privilégio dado à memória na coleta de informações e de saberes que fariam parte, que norteariam nossa trilha. Concordamos com Beatriz Sarlo (2007) quando a estudiosa argentina coloca em questão a soberania da memória para a 
construção da historicidade de determinado território. Argumentando sobre a reconstrução histórica dos dilemas argentinos na época da ditadura militar, na qual quase 40.000 pessoas desapareceram, a autora sustenta que uma época não poderia ser revisitada somente através da memória, ou seja, o testemunho não poderia ser alçado como fonte primordial de uma revisão histórica. Segundo Sarlo (2007, p. 2), “os protagonistas do passado nem sempre são os que falam, pois muitas vezes estão mortos ou preferem não falar’. Nessa direção, argumenta ser necessário recorrer a documentos escritos, às polêmicas registradas em jornais, aos panfletos distribuídos, para reconstruir a dinâmica dos anos 1960 e 1970 na Argentina. Da mesma forma, perguntamos se a trilha que desenvolvemos não poderia ser inundada, também, por histórias coligidas em documentos que atestariam, talvez em muitas direções até mesmo conflitantes, a ocupação histórica do Pântano do Sul. As fotografias, os mapas, os desenhos, os jornais de bairro, as cartas escritas por moradores, enfim, um conjunto distinto e amplo de documentos não poderia nutrir de histórias a trilha que estávamos compondo? E mais: não poderíamos ter destinado aos alunos (e, quem sabe, aos seus pais e aos seus professores) que percorreriam a trilha o privilégio de também selecionar aspectos a serem narrados e instituídos pelos caminhos daquele território?

Um terceiro aspecto a ser destacado refere-se ao privilégio dado às histórias locais, sem nos preocuparmos em conectá-las com atravessamentos mais amplos, sejam eles nacionais, sejam eles globais. Não colocamos em jogo aspectos das histórias daquela comunidade que se entremeariam com o global e com o nacional. Vimos aprendendo que o "local", o "nacional" e, também, o "global" ordenar-se-iam em níveis diferenciados. Estudar a configuração de um território através de tais noções nos exigiria pensar, portanto, nas relações entre esses níveis distintos de territorialidades. Porém, antes de construirmos uma argumentação que poderia configurar oposições, mesmo que relacionáveis, entre, por exemplo, o local e o global, não seria mais interessante perguntarmos por aspectos que estariam em jogo na ocupação de um território, sejam eles "locais" ou "globais"? Nessa direção argumentativa, Ortiz (2003, p. 61) propõe pensarmos o território "como um conjunto de planos atravessados por processos sociais diferenciados". Tal entendimento nos permitiria refletir sobre um território a partir dos seus atravessamentos (que seriam de distintas 
ordens), ou seja, precisaríamos estudá-los em suas materialidades contingentes, pois cada territorialidade diria respeito ao "cruzamento de diferentes linhas de força no contexto de uma situação determinada" (ORTIZ, 2003, p. 65). Como argumentam Scotto, Carvalho e Guimarães (2007):

Antes de querer marcar o que de local, nacional e global há em um território, ou, ainda, de buscar enxergar as relações entre eles, impõe-se uma tentativa de analisar os modos como o território em estudo foi sendo preenchido de pessoas, histórias, símbolos, enfim, de significações em um momento específico, em uma circunstância precisa.

Uma última questão com relação à nossa experiência com a construção da trilha no Pântano do Sul diz respeito à pergunta sobre quem concebeu a narrativa colocada à disposição dos caminhantes no percurso que se ia percorrer. Quem perguntou, falou, explicou, ensinou e quem ouviu, escutou, aprendeu? Fomos nós, mesmo assumindo uma posição de coletores e de contadores de histórias da comunidade, que definimos aquilo que seria reverberado através de nossas bocas. Aos nossos alunos e aos professores reservamos o "direito" da escuta, já que as perguntas que eles formulavam foram inseridas, nas nossas respostas, na gramática narrativa que privilegiamos. Sabemos que uma trilha interpretativa exigiria um guia que funcionaria como um educador ambiental. Sabemos também que no caminho a ser percorrido quase sempre se delineiam alguns pontos de parada, alguns lugares onde haveria "coisas" que necessitariam de explicação (as histórias que queríamos contar e/ou recontar). Neles, as perguntas poderiam ser feitas, porém elas seriam, quase sempre, derivações da explicação, ou seja, decorrências daquilo que na trilha havia se transformado em conteúdo pedagógico da Educação Ambiental. Como perguntou Guimarães (2005):

E se a trilha fosse à noite (na madrugada)? E em uma noite de lua nova, em uma escuridão que nos exigiria escutar, tatear, cheirar para podermos nos movimentar. E se ela fosse nas ruas e praças do bairro onde moramos e fosse feita totalmente em silêncio. Que cheiros e sabores nos inundariam? Que perguntas nos mobilizariam? E se de repente aquelas ruas tão familiares durante o dia, forem tão estrangeiras, tão estranhas, tão misteriosas durante a noite? $\mathrm{Na}$ penumbra de uma madrugada silenciosa e sombria. (...) E se a trilha, nas ruas e praças que nos são tão familiares, fosse mesmo durante o 
dia, mas, agora, feita sem termos lugar algum aonde chegar, sem termos pressa alguma ao caminhar, sem querermos pergunta alguma fazer. Aquelas ruas tão familiares nos seriam de repente assustadoramente estrangeiras? Que educação ambiental seria produzida nessa trilha onde algo tão familiar nos parece, ao mesmo tempo, tão estrangeiro?

\section{Trilhas em áreas de preservação ambiental: disciplinamento dos visitantes e produção de uma natureza intangível}

Nesta seção, embrenhamo-nos nos itinerários das trilhas que se localizam em áreas destinadas à conservação da natureza. Esta discussão se referencia especificamente em uma experiência realizada com as trilhas do Parque Estadual de Itapuã (Viamão-RS) ${ }^{3}$, mas apresenta questionamentos que podem inspirar outras práticas e outras reflexões acerca da utilização de trilhas interpretativas em locais preservados.

O que uma trilha em uma área de preservação ambiental ensina às pessoas que a percorrem? Como um trajeto geográfico pode educar através do contato com a natureza? Essas perguntas costumam nortear o planejamento de trilhas interpretativas em áreas protegidas como as Unidades de Conservação (UCs). O objetivo principal da implantação de trilhas em áreas naturais é propiciar que os visitantes possam aprender a partir da sensibilização promovida pelo contato com a natureza, além de vivenciarem uma experiência lúdica. Entende-se que a prática de caminhar em ambientes naturais possibilite uma melhor compreensão do meio ambiente e de suas inter-relações, aguçando, ainda, uma dinâmica de observação, de reflexão e de sensibilização para com as questões relativas ao meio ambiente (CARVALHO; BOÇÓN, 2004).

Entretanto, pretendemos suscitar outras possibilidades de respostas às perguntas acima e, principalmente, formular outras questões que levem a pensar sobre tais atividades de Educação Ambiental. Em primeiro lugar, porque a abordagem que empreendemos neste texto, a partir do viés dos estudos culturais, permite conferir às palavras "ensinar" e "educar" - grifadas nas perguntas expostas no parágrafo anterior conotações um pouco diversas de outras vertentes que se ocupam das práticas educativas. Isso porque a articulação entre a educação e os estudos culturais promove alguns deslocamentos no debate pedagógico contemporâneo que nos parecem importantes, como, por exemplo, 
“entender como os saberes são produzidos por determinados discursos e como tais discursos se ligam ao poder, regulam as condutas, formam ou constroem identidades e subjetividades" (WORTMANN, 2005, p. 51). Outro ponto que nos interessa é discutir quais leituras da natureza estão sendo construídas nessas atividades de Educação Ambiental; como se produz a natureza (e um modo de agir em relação a ela) a partir das práticas e dos discursos envolvidos desde o planejamento e a implantação de uma trilha interpretativa até o momento em que é desenvolvido um trabalho educativo em tais espaços.

Tratando especificamente do planejamento de trilhas em uma unidade de conservação, é preciso seguir as determinações expressas no seu Plano de Manejo ${ }^{4}$. Ou seja, há normas que devem ser respeitadas para que se assegure a preservação da área em questão. No caso do Parque Estadual de Itapuã, o Plano de Manejo (1997) prevê que as trilhas devem ser sempre orientadas por guias e que elas possuem capacidade de carga (o limite de pessoas que podem percorrer a trilha a cada dia) previamente definida. Essa capacidade de carga é calculada com base na estimativa de potenciais impactos ambientais e varia conforme o tipo de ambiente onde a trilha se localiza 5 .

Esses seriam, portanto, elementos pragmáticos que devem ser levados em consideração em um momento anterior às atividades de Educação Ambiental propriamente ditas que são realizadas nesses locais. Gostaríamos de destacar, nesse ponto, o quanto essas práticas são articuladas a discursos científicos, os quais determinam, regulam e disciplinam o uso que se faz de tais espaços. Como em muitas outras iniciativas relacionadas aos movimentos ambientalistas, a ciência atua como $a$ instância autorizada a reger as ações humanas, porque seria provida de critérios suficientemente claros, objetivos, rigorosos e, até, inquestionáveis acerca dos modos corretos de interagir com a natureza, por exemplo.

Não obstante, existem algumas correntes teóricas, como os estudos culturais de ciência ${ }^{6}$, que buscam se distanciar dessa tendência que trata a ciência como um conjunto de conhecimentos capazes de serem desconectados das instâncias contingentes em que foram produzidos e às quais eles se referem (WORTMANN; VEIGA-NETO, 2001). Nesse sentido, os estudos culturais propiciam que se entendam as categorias que aprendemos como próprias ou inerentes às diferentes áreas científicas 
como construções/invenções operadas na cultura. Através dessa perspectiva, as normas estabelecidas para o uso de áreas de preservação são entendidas como inseridas em uma trama de relações de saber, movidas por vontades de poder.

Isso fica mais evidente quando enfocamos a outra orientação contida no Plano de Manejo do Parque Estadual de Itapuã: a necessidade de que a trilha seja conduzida por um guia apto a executar essa função. Cabe mencionar que nem todas as áreas de preservação adotam esse critério; em algumas delas há trilhas autoguiadas, isto é, que não requerem a presença de um guia. Geralmente, essas trilhas se situam em lugares "menos intangíveis" - aqueles que estão sujeitos a menos riscos. Essas trilhas, por outro lado, possuem painéis explicativos ao longo do seu trajeto ou manuais que orientam o visitante, tendo em vista a ausência das informações fornecidas pelo guia. Assim, a necessidade do guia não se justifica unicamente pela relevância das explicações transmitidas em tempo real (já que placas indicativas ou livretos impressos podem substituí-lo sem grandes prejuízos). Por que, então, preconiza-se que determinadas trilhas interpretativas (como as do Parque Estadual de Itapuã) devem ser visitadas apenas na presença de uma pessoa autorizada a atuar como guia?

Como abordaremos em seguida, não estamos menosprezando a importância da atividade do guia no sentido de mostrar o que ver na trilha, como ver e quando ver. Mas, por ora, pretendemos destacar a produtividade exercida pelo guia (também chamado de condutor ou monitor) no que concerne à vigilância e ao disciplinamento dos "sujeitos-visitantes". Mais precisamente falando, há uma série de regras de conduta que devem ser seguidas pelos visitantes em uma trilha e que, em geral, são especificadas em um momento inicial da atividade. Desse modo, o visitante deve caminhar em fila indiana, respeitando o traçado da trilha; não deve correr ou ultrapassar o guia, que se posiciona sempre na dianteira do grupo; não deve falar alto para não assustar os animais; não deve retirar nenhum souvenir (plantas, pedras ou animais do local); e, por fim, deve estar atento às falas do guia.

Portanto, além de fornecer informações e indicar o caminho correto aos visitantes, os guias têm a função de monitorá-los no decurso da atividade. Ou seja, os guias estabelecem o que pode e, principalmente, o que não pode ser feito na trilha. Essa forma de disciplinamento dos corpos exercida durante tal atividade procede a partir de uma observação 
constante, constituindo o que Foucault (2005) chama de vigilância. No entanto, muito mais do que uma obediência, as ações do guia visam a uma incitação de atitudes, demarcando uma "política de coerções sutis aplicada sobre o corpo em todos seus elementos, gestos e comportamentos" (FONSECA, 1995, p. 51). Por isso, é importante destacar que

a vigilância como instrumento da disciplina é que permite a esta estratégia de poder não necessitar recorrer à força para se realizar. Ela transfere a necessidade de qualquer limitação sobre o vigiado a ele mesmo. Cabe ao próprio indivíduo aplicar sobre si o que tiver de ser aplicado (FONSECA, 1995, p. 55).

No momento em que se enfatiza a importância da preservação do local onde está situada a trilha interpretativa, pontuando as ações que colocam em risco essa preservação, supõe-se que o guia não precisa atuar no sentido de constranger ou coagir o visitante para que ele respeite tais normas, já que este, previamente informado, pode regular a própria conduta de acordo com essas regras (como também controlar as atitudes de outros visitantes que não se comportem de maneira adequada). Ao guia, atribui-se o papel de realizar a vigilância, isto é, a observação contínua dos corpos dos visitantes.

Dedicamos-nos até então a discutir como se educa nas trilhas interpretativas localizadas em áreas preservadas. Voltamos nossa atenção, agora, ao qualificativo "interpretativas" que caracteriza as trilhas nas quais se desenvolvem atividades de Educação Ambiental. De que formas a natureza é interpretada nas trilhas de Educação Ambiental? Quem são os intérpretes? Como essas interpretações constroem a natureza nessas atividades? Formulamos essas perguntas não com o intuito de desenvolvê-las neste texto, o que não seria possível, tendo em vista sua dimensão e a amplitude de vias que podemos seguir a partir desses questionamentos. Porém, essas questões podem nos dar a pensar... Ou seja, abrir trilhas de reflexão que possam ser percorridas por nós em trabalhos futuros, como também que possam ser desbravadas por outros pesquisadores que desejarem seguir nessa direção.

Mas, adiantando algumas dessas reflexões, podemos considerar que, nas áreas de preservação ambiental, as histórias contadas nas trilhas não incluem as experiências vividas pelos seres humanos nesses espaços, enfatizando apenas os aspectos biológicos, ecológicos, geográficos, entre 
outros provenientes das "ciências naturais". Demarca-se, com isso, a (antiga) separação entre natureza e cultura, esquecendo-se que a própria definição de uma área destinada especificamente à preservação dos recursos naturais é uma produção humana, uma produção cultural.

Em outros casos, como nas trilhas do Parque Estadual de Itapuã, as histórias contadas lembram da presença humana nesses locais por meio da indicação dos impactos ambientais causados pelos seres humanos em tais ambientes. Mostrando a vegetação ocupando áreas onde antes eram residências, as espécies exóticas que foram ali introduzidas pelos antigos moradores (e que devem ser eliminadas por não fazerem parte desse ecossistema ${ }^{\top}$, os locais de onde funcionavam pedreiras ${ }^{8}$, busca-se explicitar os danos causados pelas pessoas que habitavam esse lugar. Agora, quando não há mais a ação antrópica sobre esse ambiente, a natureza pode regenerar-se, voltar a ser o que era antes da ocupação humana. Essa natureza isolada por meio de cercas, "intangível", seria, então, a natureza pura e autêntica.

Cabe perguntar: todas as marcas do homem sobre a natureza são negativas? Talvez essa seja uma interpretação que prevaleça nas atividades realizadas nas trilhas em áreas preservadas. Uma interpretação que podemos - e devemos - problematizar em nossas pesquisas e em nossas práticas educativas.

\section{Algumas palavras finais}

Nas duas experiências que relatamos neste texto, os usos de trilhas interpretativas assumem perspectivas diferentes e até mesmo antagônicas. Trata-se de uma pequena amostra dos caminhos divergentes e variados pelos quais as práticas em Educação Ambiental podem ser conduzidas. E, mais uma vez, explicita-se a multiplicidade de vieses e tendências que se agrupam sobre a denominação comum de Educação Ambiental. Não temos a pretensão de encontrar ou consolidar uma Educação Ambiental que pudéssemos chamar de "nossa", como uma terra prometida, como problematiza Isabel Carvalho (2004), mas, ao mesmo tempo, buscamos construir um espaço onde possam habitar os nossos questionamentos e as nossas convicções nesse grande emaranhado discursivo que constitui o campo da Educação Ambiental. 
Para isso, entendemos como necessário o trabalho de dar visibilidade aos contrastes e distinções entre as teorizações, práticas e discursos que constituem nossa maneira de operar com a Educação Ambiental e as demais formas de se pensar e lidar com ela. É muito bemvinda a proliferação dos modos de pensar e fazer Educação Ambiental que presenciamos nestes tempos. Apesar disso, acreditamos ser preciso definir os limites e diferenciações entre essas diferentes perspectivas, para que se evite uma unificação indevida dos pontos de vista e dos referenciais que caracterizam cada uma, como também para que as críticas e problematizações deflagradas entre essas vertentes não sejam ofuscadas ou minimizadas. Isso não quer dizer que o diálogo entre elas seja inviável. Como propõe Carvalho (2004),

vale a pena fazer [...] a explicitação das diferenças, de modo a contribuir para o aumento da legibilidade e, consequentemente, formulação e assunção de práticas de educação ambiental mais conseqüentes com suas premissas, melhorando as condições do encontro, intercâmbio e do debate neste campo educativo (CARVALHO, 2004, p. 17).

Partindo em direção a esse aumento da legibilidade entre os diferentes discursos que constituem o campo da Educação Ambiental, destacamos que as análises empreendidas neste texto situam-se no terreno multifacetado e contestado dos estudos culturais. Com o intuito de discutir algumas práticas que se utilizam das trilhas interpretativas como dispositivo pedagógico, apresentamos uma experiência que relata e problematiza a interpretação de uma trilha em que não se objetiva demarcar e reforçar a separação entre cultura e natureza, entre o que é humano e o que é natural. Essa discussão nos parece bastante importante, pois os estudos que temos desenvolvido preocupam-se destacadamente com os modos como a natureza é culturalmente construída em diferentes instâncias (não apenas nas práticas de Educação Ambiental).

Por outro lado, realizamos uma análise (posicionada a partir de nossas preferências teóricas, cabe realçar) das atividades realizadas em uma trilha interpretativa localizada em uma Unidade de Conservação. Nessa análise, efetivamos alguns deslocamentos em uma série de práticas comuns a algumas correntes da Educação Ambiental. O uso da palavra deslocamento é, aqui, pertinente, pois a discussão que realizamos não pretendeu desmerecer nem desvalorizar essas atividades. Como dissemos 
no início do texto, essas práticas atravessam nossa constituição enquanto educadores. Mas, a partir do nosso posicionamento como pesquisadores no campo dos estudos culturais, acreditamos que é importante e necessário deslocar nossas certezas, colocar em suspenso aquilo que pensávamos que era inquestionável.

Além disso, realçamos que, ao problematizarmos as trilhas interpretativas realizadas nas áreas preservadas, esmiuçando alguns de seus aspectos aparentemente técnicos, não estamos, de modo algum, supondo que essas atividades não sejam eficazes em produzir os efeitos para os quais são propostas. Muito pelo contrário: são justamente os aspectos relacionados à produtividade exercida por essas atividades na subjetivação de indivíduos e na instituição de discursos acerca da natureza e suas relações (entre tantos outros discursos que circulam nessas atividades) que nos interessamos em focalizar.

\section{Referências}

CARVALHO, Isabel Cristina M. Educação Ambiental Crítica: nomes e endereçamentos da educação. Ministério do Meio Ambiente. Diretoria de Educação Ambiental; Philippe Pomier Layrargues (Org.). Identidades da educaşão ambiental brasileira. Brasília: Ministério do Meio Ambiente, 2004.

CARVALHO, Joema; BOÇÓN, Roberto. Planejamento do traçado de uma trilha interpretativa através da caracterização florística. Revista Floresta, Curitiba, v. 34, n. 1, p. 23-32, jan./abr., 2004.

FONSECA, Márcio A. Michel Foucault e a constituição do sujeito. São Paulo: EDUC, 1995. FOUCAULT, Michel. Vigiar e punir: história da violência nas prisões. Petrópolis: Vozes, 2005.

GUIMARÃES, Leandro Belinaso. A natureza na arena cultural. Jornal A Página. Portugal: ano 15, número 155, página 7, abril, 2006. Disponível em:

$<$ http://www.apagina.pt/arquivo/Artigo.asp?ID=4517>. Acessado em 5/3/2007.

GUIMARÃES, Leandro Belinaso. É possível um território familiar estar ao mesmo tempo estrangeiro? In: SKLIAR, Carlos (Org.). Derrida e a Educação. Belo Horizonte: Autêntica, 2005.

GUIMARÃES, Leandro Belinaso; SANTOS, Rodrigo. Discutindo o cruzamento de saberes em uma prática educativo-ambiental. Revista Educaşão: Teoria e Prática. UNESP/Rio Claro, 2001 (CD-ROM).

RIO GRANDE DO SUL. Plano de Manejo: Parque Estadual de Itapuã. Porto Alegre: Departamento de Recursos Naturais Renováveis, 1997.

SANTIAGO, Silviano. O entre-lugar do discurso latino-americano. In: SANTIAGO, Silviano. Uma literatura nos trópicos: ensaios sobre dependência cultural. Rio de Janeiro: Rocco, 2000. 
SARLO, Beatriz. O terror e a memória num beco sem saída. In: FILHO, Antonio Gonçalves (entrevistador). O Estado de São Paulo (Caderno Cultura), 1 de abril de 2007. SCOTTO, Gabriela; CARVALHO, Isabel; GUIMARÃES, Leandro Belinaso. Desenvolvimento Sustentável. Petrópolis: Vozes, 2007.

ORTIZ, Renato. Um outro território: ensaios sobre a mundialização. São Paulo: Olho d'água, 2003.

WORTMANN, Maria Lúcia C.; VEIGA-NETO, Alfredo. Estudos Culturais da Ciência e Educação. Belo Horizonte: Autêntica, 2001.

WORTMANN, Maria Lúcia C. Dos riscos e dos ganhos de transitar nas fronteiras dos saberes. In: COSTA, Marisa V.; BUJES, Maria Isabel E. (Orgs.). Caminhos Investigativos III: riscos e possibilidades de pesquisar nas fronteiras. Rio de Janeiro: DP\&A, 2005.

\section{Notas}

${ }^{1}$ Encontro de Pesquisa em Educação Ambiental.

${ }^{2}$ Ver em Guimarães e Santos (2001) o processo que culminou na seleção da água como temática do nosso projeto.

${ }^{3}$ Destacamos que este relato baseia-se na vivência de um dos autores deste texto como coordenador de Educação Ambiental deste parque, ocorrida de 2001 a 2003. Vale comentar que o Parque Estadual de Itapuã foi aberto à visitação pública no início de 2002 e, portanto, no período antecedente foi necessário planejar e implantar as trilhas que seriam disponibilizadas aos visitantes, bem como treinar os guias e monitores para realizarem a condução nessas trilhas.

${ }^{4}$ Plano de manejo é um documento que especifica o que pode ser feito na área preservada e como deve ser feito. Sua elaboração é encomendada a uma equipe técnica capaz de realizar todos os levantamentos necessários. Muitas vezes, empresas de consultoria ambiental são contratadas para executar esse serviço.

${ }^{5}$ Por exemplo, considera-se neste cálculo o índice pluviométrico anual, a presença de trechos íngremes, a porosidade do terreno, entre outros aspectos.

${ }^{6}$ Ver, por exemplo, o livro Estudos culturais de ciência \& educação, de Maria Lúcia Wortmann e Alfredo Veiga-Neto (2001).

${ }^{7}$ A presença de espécies exóticas utilizadas no paisagismo contrapõe os objetivos das atividades de interpretação da natureza, o que sugere o manejo das mesmas através de sua retirada gradativa, no caso da implantação da trilha interpretativa (CARVALHO; BOÇÓN, 2004).

${ }^{8}$ Uma atividade comum no local onde é, atualmente, o Parque Estadual de Itapuã era a extração de granito rosa, rocha abundante nessa região. O início da agitação promovida por ambientalistas (entre eles o gaúcho José Lutzemberger) para efetivar o local como uma área destinada à conservação da natureza, na década de 1970, deveu-se aos impactos ambientais provocados pela mineração. 
Recebido: 30/03/09

Aprovado: 14/08/09

Contato:

Universidade Federal de Santa Catarina

Centro de Ciências da Educação

Departamento de Metodologia de Ensino

Campus Universitário

Trindade

Caixa Postal 476

CED/MEN sala 212

Florianópolis - SC

CEP 88040-900 